\title{
PÓS-GRADUAÇÃO: METODOLOGIA PARA REESTRUTURAÇÃO DE LINHAS DE PESQUISA
}

\section{Graduate Program: Methodology for Restructuring of Research Lines}

\author{
Prof ${ }^{a}$. Dra . Silvia Aparecida Guarnieri Ortigoza \\ Pós-Graduação em Geografia da Universidade Estadual Paulista - Rio Claro \\ Av. 24-A n. 1515 - Bela Vista - CEP 13506-900, Rio Claro (SP) - Brasil \\ Tel.:(+ 55 19) 35269212 - sago@rc.unesp.br \\ Prof ${ }^{\mathrm{a}}$. Dra . Lígia Celoria Poltroniéri \\ Universidade Estadual Paulista - Rio Claro \\ cpligiaonline@hotmail.com
}

Prof ${ }^{\mathrm{a}}$. Dra . Lucy Marion Calderini Philadelpho Machado

Universidade Estadual Paulista - Rio Claro

lucy-machado@hotmail.com

\section{${ }_{a} a \boldsymbol{a a a}_{a}$}

\begin{abstract}
Resumo
O objetivo deste artigo é apresentar uma proposta metodológica baseada na análise das palavras-chave das Dissertações e Teses no Programa de Pós-Graduação em Geografia do IGCE/UNESP, Campus de Rio Claro-SP. Este Programa, instalado no IGCE/UNESP/Rio Claro, no ano de 1976, iniciou suas atividades acadêmicas em 1977, em nível de Mestrado e, em 1983, em nível de Doutorado. Nestes 31 anos de existência consolidou-se no âmbito da Pós-Graduação brasileira e, em especial, no campo da ciência geográfica formando grande número de profissionais. A metodologia utilizada baseou-se na coleta e agrupamento de 1324 palavras-chave inseridas nas Dissertações e Teses defendidas a partir de novembro de 1992, permitindo a definição dos eixos temáticos efetivamente pesquisados. Os resultados obtidos, altamente confiáveis, poderão subsidiar a reestruturação das linhas de pesquisa do Programa, de forma mais fiel à sua produção acadêmica além do que, a metodologia utilizada poderá ser aplicada a todo e qualquer Programa de Pós-Graduação.
\end{abstract}

Palavras-chave: metodologia, pós-graduação, agrupamento, similaridade/sinonímia, eixos temáticos.

\begin{abstract}
The aim of this paper is to present a methodology based on analysis of the keywords of Dissertations and Theses in the Graduate Program in Geography IGCE / UNESP, Rio Claro-SP. This Program, installed on IGCE / UNESP / Rio Claro, in 1976, started its academic activities in 1977, Master Degree, and in 1983 in a Doctoral degree. In these 31 years consolidated within the Graduate Brazilian and in particular in the field of geographical science forming large number of professionals. The methodology was based on the collection and cluster of 1324 keywords entered in Dissertations Theses and defended from November 1992, allowing the definition of the axes thematic effectively researched. The results, highly reliable could subsidize the restructuring of the research lines of the Program, more faithful to his academic production beyond what the methodology can be applied to any Graduate Program.
\end{abstract}

Key words: methodology, graduate, geography, cluster, similarity / synonymy, themes.

\section{Resumen}

El objetivo de este artículo es presentar una propuesta metodológica basada en el análisis de las palabras clave de las Disertaciones y Tesis en el Programa de Postgrado en Geografía del IGCE/UNESP, Campus de Rio Claro - SP. Este programa, instalado en 1976 en el IGCE/UNESP/Rio Claro, empezó sus actividades académicas en el nivel de Maestría en 1977 y, en el nivel de Doctorado en 1983. En estos 31 años de existencia se consolidó en el ámbito del postgrado brasileño y, sobretodo, en el campo de la ciencia geográfica, formando un gran número de profesionales. La metodología aplicada está basada en la recolección y categorización de 1324 palabras-clave insertas en las Disertaciones y Tesis defendidas desde noviembre de 1992, permitiendo la definición de los ejes temáticos que han sido efectivamente investigados. Los resultados obtenidos, altamente confiables, podrán ayudar a la restructuración de las líneas de investigación del Programa de una manera más fiel a su producción académica al mismo tiempo que la metodología utilizada podrá ser aplicada a cualquier programa de postgrado.

Palabras clave: metodología, postgrado, geografía, categorización, semejanza/sinonimia, ejes temáticos.

\section{aaAaa}

Revista da ANPEGE, v. 7, n. 8, p. 143-154, ago./dez. 2011.

ISSN 1679-768 X @ 2003, Associação Nacional de Pesquisa e Pós-Graduação em Geografia. Todos os direitos reservados. 


\section{INTRODUÇÃO}

Os Programas de Pós-Graduação brasileiros têm sido chamados a enfrentar novos desafios no âmbito da Avaliação da CAPES. Para o Programa de Pós-Graduação em Geografia da UNESP de Rio Claro, no período da gestão 2007-2010, o maior desses desafios consistiu na manutenção da qualidade da formação. A grande questão colocada foi a de como assegurar a existência de uma especialização de qualidade visando, em última instância, o desenvolvimento do país quando se têm pela frente a existência de uma forte pressão "produtivista", além da grande competitividade na política de fomento.

Sem desconsiderar a necessidade de ajustes e debates acerca da pressão do aumento da produção e a crítica continuada da sujeição à política de fomentos, o mais importante de todos esses desafios foi reconhecer tanto as competências internas representadas pelos docentes credenciados como a dos grupos de pesquisa. A meta, a curto prazo foi procurar conhecer a realidade da produção local com o objetivo de, a médio prazo, enriquecer as disciplinas a serem ministradas e as pesquisas a serem estimuladas. Conhecer a própria realidade significa uma coleta e análise de informações contidas nas Teses e Dissertações defendidas, com o objetivo central de reestruturação e fortalecimento das linhas de pesquisa, dando-lhes maior consistência e coerência com o perfil geral do Programa.

É notório que dentro dos diversos aspectos a serem auto-avaliados em qualquer Programa de Pós-Graduação a criação, a reestruturação e a estabilização das linhas de pesquisa configuram itens de extrema importância.

(...) a autoavaliação, veementemente contestada por aqueles que propugnavam a objetividade na avaliação e, por isto mesmo, defendiam exclusivamente um modelo de avaliação externa, hoje deixa de ser vista como um mecanismo de autoproteção dos programas frente a eventuais resultados negativos decorrentes da avaliação externa. Esta modalidade de avaliação passa a ser proposta e discutida como um caminho que, ao lado da avaliação externa, pode compor um modelo interessante e valioso, com vistas ao aperfeiçoamento dos programas. (SAUL, 2002,p. 100).

A auto-avaliação deve ser sistemática, pois à medida que o Programa vai se consolidando surgem, obrigatoriamente, novas especialidades, novas disciplinas, novos docentes são credenciados, contribuindo para definir outras temáticas de pesquisa diferentes, em maior ou menor grau, daquelas existentes à época de implantação do Programa. Deste modo, entre os mais diversos aspectos a serem avaliados, torna-se premente a avaliação e reestruturação das linhas de pesquisa visando a atender às mudanças exigidas tanto pelo alunado quanto pelos docentes credenciados.

É importante destacar que, na literatura internacional sobre Avaliação Educacional, a polarização que se instalou entre a avaliação externa e a auto-avaliação, contrapondo-se uma à outra, é questão solucionada de há muito. É consenso, portanto, que estas duas modalidades se complementam, apresentando-se como dimensões importantes de um mesmo processo de avaliação educacional. Trata-se, portanto de, ao lado de ressignificar a auto-avaliação, no contexto da avaliação de um Programa de Pós-Graduação, encontrar uma arquitetura para a mesma que explicite os seus fundamentos teórico-metodológicos e que enseje uma prática viável, cujos resultados possam ser reconhecidos como importantes para a melhoria dos Programas. (SAUL, 2002, p. 100)

Um dos grandes problemas é definir os critérios nos quais a avaliação e a reestruturação serão baseadas para que possam, efetivamente, retratar o perfil temático de cada Programa. Normalmente, ocorrem reuniões entre a Coordenação, os docentes e representantes discentes onde as sugestões são apresentadas, discutidas e aprovadas, chegando-se à definição das linhas de pesquisa que nortearão o desenvolvimento das atividades do Programa, por determinado período.

Com esta política, nem sempre é possível atender a todas as expectativas e os resultados deixam a desejar, seja pela excessiva pulverização, seja pela excessiva concentração. O Programa de Pós-Graduação aqui analisado apresentou, ao longo de seu processo de consolidação, esses dois 
problemas com suas linhas de pesquisa: ora a pulverização ora, a concentração.

Mas, conforme adverte FREIRE (1990): "a avaliação da prática revela acertos, erros e imprecisões. A avaliação corrige a prática, melhora a prática, aumenta a nossa eficiência” (p. 77).

Nesse contexto, o objetivo deste artigo é apresentar uma proposta metodológica de análise baseada, unicamente, na produção acadêmica do Programa a qual, certamente, refletirá o real perfil definindo os eixos temáticos efetivamente pesquisados. Acredita-se que a fidelidade dos dados coletados permitirá uma reestruturação coerente que representará maiores chances de sucesso nos novos desafios a serem enfrentados pelo Programa.

\section{O PROGRAMA DE PÓS-GRADUAÇÃO EM GEOGRAFIA DA UNESP, CAMPUS DE RIO CLARO (SP) E SEU PROCESSO DE AUTO-AVALIAÇÃO}

Este Programa foi instalado no Instituto de Geociências e Ciências Exatas (IGCE), UNESP/ Rio Claro, no ano de 1976 e as atividades acadêmicas tiveram início em 1977, em nível de Mestrado e, em 1983, em nível de Doutorado. Neste período de existência, 31 anos, foram defendidos 480 trabalhos de pesquisa, sendo 317 Dissertações de Mestrado e 163 Teses de Doutorado.

Trata-se, portanto, de um Programa consolidado no âmbito da Pós-Graduação brasileira e, em especial, no campo da ciência geográfica, tendo em vista a formação de inúmeros profissionais que atuam tanto em instituições de ensino superior, públicas e particulares, como também em institutos de pesquisa, empresas e instituições de ensino fundamental e médio.

No que se refere às linhas de Pesquisa do Programa, nos primeiros vinte anos, portanto, de 1977 à 1997, havia 15 linhas, ampliadas para 19 no período 1998/2000. De 2001 à 2003 houve uma redução para 8, depois para 4 ( de 2004 à 2006) e, finalmente, para 2 linhas de pesquisa desde 2007, conforme o Quadro 1.

A Pró-Reitoria de Pós-Graduação da UNESP tem, sistematicamente, se manifestado pela necessidade de reestruturação, uma vez que as linhas existentes atualmente são extremamente genéricas, permitindo que pesquisas muito diferenciadas integrem uma mesma linhas.

Assim, com vistas a alcançar a qualidade e a excelência, o Conselho do Programa, na gestão 2007/2010, procurou estabelecer um critério que retratasse mais fiel e adequadamente a produção acadêmica do Programa, desde a sua implantação.

Sobre esta busca da qualidade GALVÃO (2007), acrescenta que:

O ensino qualificado da Geografia em todos os níveis impõe-se, portanto, como uma necessidade inadiável. Para tanto, a Pós-Graduação se coloca como fonte geradora do próprio conhecimento geográfico e base realimentadora da formação de profissionais para o magistério e para o atendimento de usuários da geografia, no mercado de trabalho e no Planejamento (p. 5).

Buscando a maior aproximação possível da realidade da produção acadêmica do Programa, optou-se por utilizar as palavras-chave inseridas nas Dissertações e Teses defendidas. Este procedimento pôde ser adotado porque, a partir de novembro de 1992, o Parágrafo Único do artigo 47 do Regulamento do Curso de Pós-Graduação em Geografia, estabeleceu que deveriam fazer parte da Dissertação/Tese: resumo, abstract e até seis palavras-chave.

O objetivo foi determinar os grandes eixos de pesquisa do Programa no período 1992/2008, com vistas a uma possível reestruturação das linhas de pesquisa e melhor articulação com disciplinas, grupos e projetos de pesquisa e publicações. 
Quadro 1 - Programa de Pós-Graduação em Geografia da UNESP/Rio Claro -

Linhas de Pesquisa no período 1977/2008

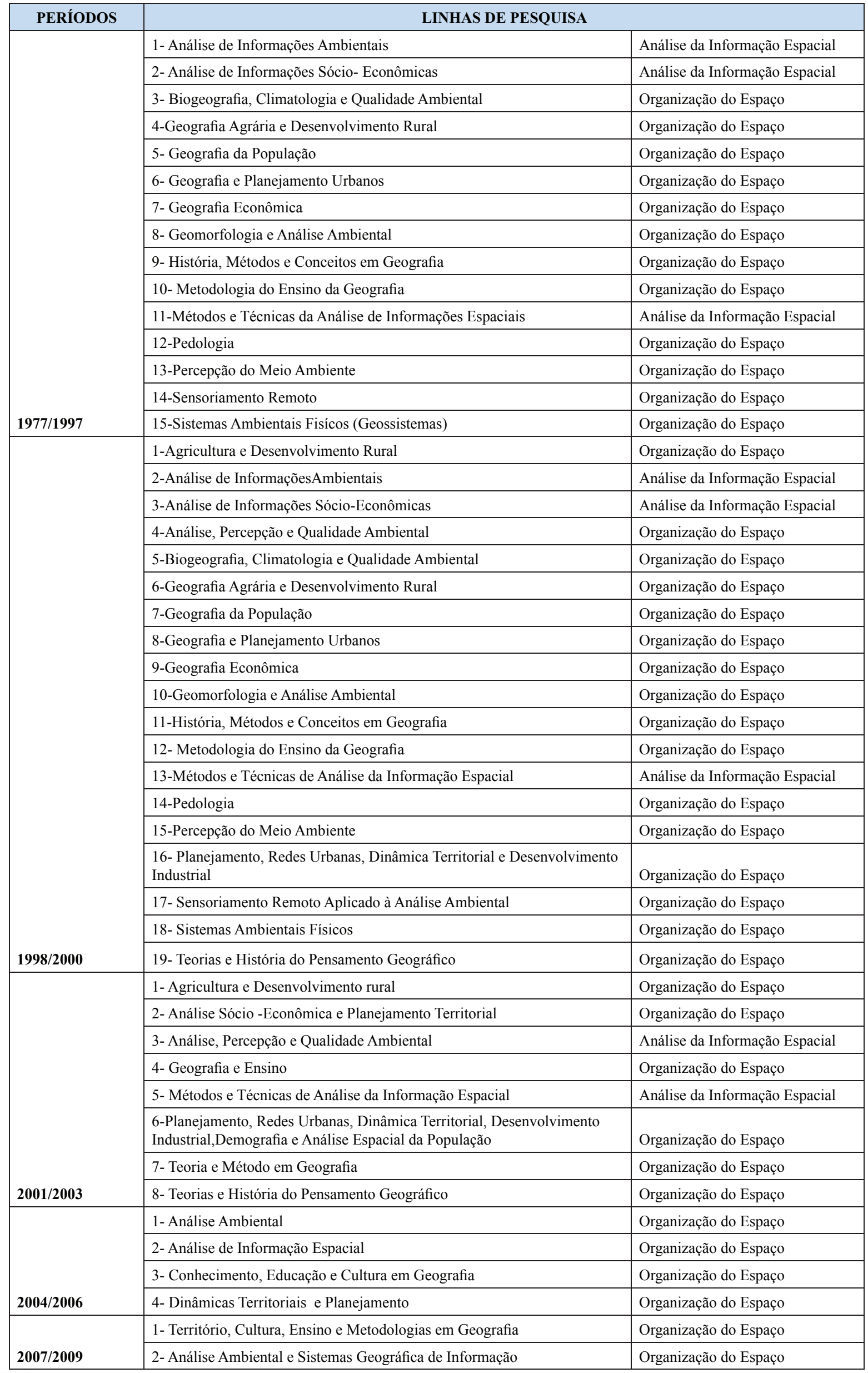


Assim, foram consideradas as palavras-chave inseridas desde a primeira Dissertação e Tese defendidas após a publicação da referida Norma, ou seja, de novembro de 1992 até dezembro de 2008, totalizando 364 trabalhos, sendo 217 de Mestrado e 147 de Doutorado.

\section{EXPLICITANDO OS FUNDAMENTOS DA METODOLOGIA ALICADA}

A escolha da metodologia de pesquisa é a etapa mais desafiante, com relação à avaliação dos Programas de Pós-Graduação. Vários geógrafos já realizaram estudos procurando retratar uma visão mais geral da produção no âmbito do perfil da Pós-Graduação em Geografia no Brasil; entre esses autores destacam-se: GERARDI (2003), DUARTE (2003), CARLOS (2003), SUERTEGARAY (2003, 2005 e 2007), MENDONÇA (2005) e SILVA E OLIVEIRA (2009).

Um exemplo desses estudos foi realizado por SUERTEGARAY (2007) que, analisando 29 Cursos, afirma:

Para fazer esta análise, avaliou-se a partir da produção de teses e dissertações dos 29 programas distribuídos em território nacional, alguns elementos que podem indicar, através do título do trabalho, atualidade e tendências. Para tanto, levantei duas dimensões que norteiam minhas preocupações: a escala de análise e os subcampos da Geografia. Considerando a escala, classifiquei os trabalhos nas escalas local, regional, nacional e abrangência internacional. A definição dos campos temáticos ( sub-unidades da Geografia) não foi feita a priori, resultou da análise do conjunto de dissertações e teses, portanto, constitui elemento de indicação de tendência. Observei, para o conjunto dos dados, temas relativos à Geografia Física, Geografia Humana, Ambiente, Educação e Geografia, Teoria e Método em Geografia. (SUERTEGARAY, p.26, 2007).

Resolvido o primeiro desafio, ou seja, a decisão de centrar a avaliação na coleta das palavras-chave inseridas nas Dissertações e Teses defendidas no Programas, a partir de novembro de 1992, o próximo passo foi o estabelecimento dos períodos de análise, em função da existência de várias e diferentes linhas de pesquisa que permearam no Programa desde sua implantação. Como estas diferentes linhas de pesquisa vigoraram durante diferentes períodos, decidiu-se que os mesmos seriam respeitados em todo o desenvolvimento da pesquisa, nos dois níveis, Mestrado e Doutorado.

Além disso, considerou-se, também, a divisão dos trabalhos produzidos nas duas Áreas de Concentração que, então, compunham o Programa: Organização do Espaço e Análise da Informação Espacial, esta última vigorando de 1998 a 2006.

A Tabela 1 resume essas informações.

Tabela 1 - Palavras-Chave - número de dissertações e teses, por períodos $(\mathrm{N}=364)$

\begin{tabular}{|c|c|c|c|c|c|c|}
\hline & \multicolumn{2}{|c|}{$\begin{array}{l}\text { ORGANIZAÇÃO DO } \\
\text { ESPAÇO }\end{array}$} & \multicolumn{2}{|c|}{ ANÁLISE DA INFORMAÇÃO ESPACIAL } & \multirow{2}{*}{\multicolumn{2}{|c|}{ \% do Total }} \\
\hline & Mestrado & Doutorado & Mestrado & Doutorado & & \\
\hline 1992/1997 & 44 & 30 & \multicolumn{2}{|c|}{ Não existia a área } & 74 & 19,23 \\
\hline $1998 / 2000$ & 19 & 28 & 4 & 5 & 56 & 15,38 \\
\hline $2001 / 2003$ & 30 & 17 & 10 & 5 & 62 & 17,03 \\
\hline $2004 / 2006$ & 59 & 36 & 7 & 7 & 109 & 29,94 \\
\hline $2007 / 2008$ & 44 & 19 & \multicolumn{2}{|c|}{ Não existe mais } & 63 & 17,3 \\
\hline Total & 196 & 130 & 21 & 17 & 364 & 100,00 \\
\hline
\end{tabular}

Org. L. Poltroniéri e L. Machado.

Observa-se que foram pesquisados 364 trabalhos, sendo 196 Dissertações de Mestrado e 130 Teses de Doutorado na Área de Concentração em Organização do Espaço e 21 Mestrados e 17 Doutorados na Área de Concentração em Análise da Informação Espacial. 
Os procedimentos metodológicos foram assim divididos:

1- Coleta de dados

A coleta de dados foi realizada, volume a volume, nas seguintes fontes: a) resumos das Dissertações e Teses existentes nos arquivos da Seção de Pós-Graduação do Instituto de Geociências e Ciências Exatas ( IGCE), UNESP, Campus Rio Claro; b) consulta à Biblioteca Digital da UNESP; c) pesquisa na biblioteca do IGCE e na Biblioteca Central da UNESP, Campus de Rio Claro; d) arquivos da Coordenação do Programa de Pós-Graduação em Geografia da UNESP, Campus Rio Claro.

De cada volume forma coletadas todas as palavras-chave indicadas pelo autor. Quando, apesar da exigência, não havia nenhuma citação, recorria-se às informações constantes na ficha catalográfica.

Das 364 Dissertações e Teses pesquisadas, apenas 26 não continham palavras-chave, nem ficha catalográfica e, nem mesmo, resumo.

\section{2 - Organização dos dados}

Separadas por períodos, de acordo com o número de linhas de pesquisa vigente por Área de Concentração ( Organização do Espaço e Análise da Informação Espacial) e por nível ( Mestrado e Doutorado), as palavras-chave coletadas foram listadas em planilhas.

A Tabela 2 resume o universo trabalhado nos dois níveis: Mestrado e Doutorado.

Tabela 2 - Mestrado e Doutorado: número total de palavras-chave nas duas áreas de concentração, no período 1992/2008 (n=1324)

\begin{tabular}{|c|c|c|c|c|c|}
\hline \multicolumn{6}{|c|}{ MESTRADO } \\
\hline \multirow[b]{2}{*}{ Períodos } & \multicolumn{2}{|c|}{ ORGANIZAÇÃO DO ESPAÇO } & \multicolumn{2}{|c|}{ ANÁLISE DA INFORMAÇÃO ESPACIAL } & \multirow[b]{2}{*}{ Total } \\
\hline & Resumos & Fichas Catalográficas & Resumos & Fichas Catalográficas & \\
\hline $1992 / 1997$ & 61 & 38 & --- & --- & 99 \\
\hline $1998 / 2000$ & 67 & 7 & 13 & 6 & 93 \\
\hline $2001 / 2003$ & 92 & 25 & 37 & 4 & 158 \\
\hline $2004 / 2006$ & 190 & 26 & 26 & 4 & 246 \\
\hline $2007 / 2008$ & 176 & 6 & --- & --- & 182 \\
\hline Total & 586 & 102 & 76 & 14 & 778 \\
\hline \multicolumn{6}{|c|}{ DOUTORADO } \\
\hline & \multicolumn{2}{|c|}{ ORGANIZAÇÃO DO ESPAÇO } & \multicolumn{2}{|c|}{ ANÁLISE DA INFORMAÇÃO ESPACIAL } & \\
\hline Períodos & Resumos & Fichas Catalográficas & Resumos & Fichas Catalográficas & Total \\
\hline $1992 / 1997$ & 85 & 11 & --- & --- & 96 \\
\hline $1998 / 2000$ & 101 & 7 & 24 & --- & 132 \\
\hline $2001 / 2003$ & 57 & 4 & 12 & 2 & 75 \\
\hline $2004 / 2006$ & 125 & 2 & 33 & --- & 160 \\
\hline $2007 / 2008$ & 67 & 16 & --- & --- & 83 \\
\hline
\end{tabular}

Org. L. Poltroniéri e L. Machado.

Observa-se que o universo da pesquisa foi composto por 778 palavras-chave coletadas nas Dissertações de Mestrado e 546 nas Teses de Doutorado, totalizando 1324.

A partir destas planilhas foi realizado o agrupamento das palavras-chave, por similaridade, sem uso de qualquer programa computacional. Esta opção foi feita para permitir um controle mais eficaz por parte das três pesquisadoras as quais, ressalte-se, são docente e ex-docentes do Programa: uma, com experiência na Coordenação nos períodos 1992/1994 e 1996/1998; outra, com dezoito anos de credenciamento e a terceira docente/coordenadora do Programa na gestão 2007/2010, todas com amplo conhecimento e familiaridade com a realidade a ser pesquisada.

Embora baseada na freqüência de citação de cada uma das palavras-chave, a análise dos dados foi qualitativa e categorial. 
3 - Agrupamento dos dados

O agrupamento dos dados foi realizado com rigor e alto nível de detalhamento.

Na primeira contagem considerou-se, apenas, as palavras-chave idênticas com mais de uma citação, nos dois níveis em separado ( Mestrado e Doutorado), em cada um dos períodos.

Conforme se observa na Tabela 3, enquadraram-se nesta categoria apenas 68 palavras no Mestrado e 42 no Doutorado, totalizando 110, ou seja, apenas 16,51\% do total de palavras-chave coletadas (1324).

Tabela 3 - Agrupamento de palavras-chave idênticas com mais de uma citação no período 1992/2008

\begin{tabular}{l|c|c}
\hline AGRUPAMENTOS & NÚMERO DE & $\begin{array}{c}\text { PORCENTAGEM } \\
\text { DO TOTAL (1324) }\end{array}$ \\
& PALAVRAS-CHAVE & \\
\hline $\mathbf{1}^{\mathbf{0}} \quad \begin{array}{r}\text { Agrupamento } \\
\text { Mestrado e Doutorado }\end{array}$ & 110 & 16,51 \\
\hline $\mathbf{2}^{\mathbf{0}}$ Agrupamento & & \\
Mestrado + Doutorado & 259 & 38,88 \\
\hline
\end{tabular}

Org. L. Poltroniéri e L. Machado.

Estes resultados foram considerados muito pouco representativos para os dois níveis, devido ao pequeno número de citações idênticas repetidas em todos os períodos.

Resolveu-se, então, analisar em conjunto a produção acadêmica do Programa (Mestrado + Doutorado) em cada um dos períodos (17 anos) observando-se, ainda, a repetição de palavras-chave idênticas.

Deste modo, conforme se observa na Tabela 3, conseguiu-se agrupar 259 palavras-chave idênticas que apareceram com mais de uma citação, ou seja, 38,88\% do total coletado.

Logo, ao considerar a repetição de palavras-chave idênticas nos dois níveis (Mestrado + Doutorado) em conjunto, conseguiu-se duplicar o percentual de aproveitamento das palavras-chave citadas de $16,51 \%$ para $38,88 \%$.

Observou-se, entretanto, que do total de palavras-chave coletadas (1324), 658 foram citadas apenas uma vez, em qualquer um dos períodos, nos dois níveis ( Mestrado e Doutorado); este número, que correspondia a $49,69 \%$ do total coletado não poderia ser desprezado.

Assim, novo agrupamento foi realizado considerando a similaridade e/ou a sinonímia de cada palavra-chave, conforme resumido na Tabela 4.

Tabela 4 - Agrupamento de palavras-chave com mais de uma citação, por similaridade e/ou sinonímia no período 1992/2008

\begin{tabular}{l|c|c}
\multicolumn{1}{c|}{$\mathbf{3}^{\circ}$ AGRUPAMENTO } & NÚMERO DE PALAVRAS-CHAVE & PORCENTAGEM DO TOTAL \\
\hline Análise Geral & 1102 & 83,24 \\
\hline $\begin{array}{l}\text { Mestrado + Doutorado Palavras-chave relacionadas a "Estudos } \\
\text { de caso" }\end{array}$ & 102 & 7,70 \\
\hline Mestrado + Doutorado Palavras-chave que não se agruparam & 120 & 9,06 \\
\hline TOTAL DE PALAVRAS-CHAVE & 1324 & 100,00 \\
\hline
\end{tabular}

Org. L. Poltroniéri e L. Machado.

Denominado de análise geral, o resultado deste terceiro agrupamento foi anexado àqueles anteriormente obtidos quando se considerou, conjuntamente, apenas as palavras-chave idênticas citadas nas Dissertações de Mestrado e nas Teses de Doutorado, em cada um dos períodos. Desta forma, o percentual de aproveitamento das palavras-chave coletadas ampliou-se de 38,88\% para $83,24 \%$ do total, isso é, 1102 palavras-chave idênticas, similares e/ou sinônimas. 
Os $16,76 \%$ restantes compreendem duas outras categorias, já descritas na Tabela 4:

. 102 palavras-chave relativas a "estudos de caso" (locais ou empresas) que representam 7,70\% do total de palavras coletado. Tais palavras-chave não podem ser consideradas como perdidas, pois, em Geografia, um dos princípios básicos é a localização espacial e muitas das pesquisas referem-se a um determinado local ou empresa, os quais são citados no título do trabalho e, consequentemente, na relação de palavras-chave;

. 120 palavras-chave que foram citadas apenas uma única vez e que não se agruparam a nenhuma outra, mesmo considerando a similaridade e/ou sinonímia, representando apenas 9,06\% do total considerado.

Entretanto, apenas, observa-se que, mesmo somando esses dois percentuais, apenas $16,76 \%$ do total de palavras-chave coletado não foi incorporado nos resultados do agrupamento.

\section{AVALIANDO OS RESULTADOS}

Os resultados do agrupamento e análise das 1324 palavras-chave inseridas nas 217 Dissertações de Mestrado e 147 Teses de Doutorado comprovaram a existência na produção acadêmica do Programa de Pós-Graduação em Geografia da UNESP/Rio Claro, de 3 categorias:

- grandes eixos temáticos consolidados e que vêm se mantendo ao longo do tempo;

. temas de pesquisa em nítido processo de consolidação;

. questões centrais que já estão se impondo de forma importante no contexto da produção geográfica contemporânea.

Considerando a evolução das linhas de pesquisa, no período 1992/2008, observou-se, de modo geral, que até 2003 quando o Programa possuía 8 linhas de pesquisa, os trabalhos produzidos apresentavam grande diversidade temática,mas podiam ser enquadrados nas linhas sem dificuldade. Entretanto, essa quantidade excessiva de linhas gerava alto nível de especificidade o que, muitas vezes, levava os docentes a orientar pesquisas em mais de uma linha.

De 2004 a 2006, com a redução para 4 linhas de pesquisa, a adequação das pesquisas tornou-se mais difícil porque este foi justamente o período, dentre os analisados, em que a produção científica do Programa foi maior ( 66 Dissertações de Mestrado e 43 Teses de Doutorado, isto é, 29,94\% da produção total do período analisado), com uma enorme pulverização de temas. Basta verificar que o número de palavras-chave citadas neste período (407) foi o dobro do primeiro período e quase o dobro de cada um dos outros três períodos analisados.

Com a ampliação no número de pesquisas e o aumento da diversificação temática, houve a necessidade de reestruturação, pois os docentes continuavam a orientar em mais de uma linha, interferindo negativamente no fortalecimento dos Grupos de Pesquisa.

De 2007 a 2008, com uma nova redução de 4 para 2 linhas de pesquisa, as dificuldades permaneceram, pois as temáticas estudadas continuaram variadas sendo extremamente difícil classificar a pesquisa numa determinada linha, ou seja, muitas pesquisas poderiam se enquadrar tanto em uma como em outra linha.

Esta dificuldade de retratar o perfil do Programa através das linhas de pesquisa é geral na área geográfica, onde se tem vários docentes/pesquisadores focados em um tema, e outros que optam por uma diversidade temática em sua grande área do conhecimento, grosso modo: Geografia Física e/ou Geografia Humana. Essa liberdade dos geógrafos, apesar de gerar um aprofundamento do conhecimento em diversos temas e uma multidisciplinaridade cria, também, sérias dificuldades no atendimento às demandas desse conjunto tão amplo e diversificado de pesquisadores. Cabe ressaltar que, atualmente, o Programa conta com um quadro de 33 docentes credenciados. 
O resultado final do agrupamento das palavras-chave, por similaridade e sinonímia, está resumido nas Tabelas 5, 6 e 7 .

Tabela 5 - Agrupamento das palavras-chave das dissertações e teses no período 1992/2008 (n=600) - eixos temáticos consolidados.

\begin{tabular}{|c|c|c|}
\hline EIXOS TEMÁTICOS CONSOLIDADOS & $\begin{array}{l}\text { NÚMERO DE } \\
\text { CITAÇÕES }\end{array}$ & $\begin{array}{l}\text { PORCENTAGEM } \quad \text { EM } \\
\text { RELAÇÃO TOTAL }\end{array}$ \\
\hline Geografia Urbana (110) + cidades(12)+urbanização(9 & 131 & 9.90 \\
\hline Geomorfologia(54)+bacia hidrográfica(17)+erosão(16) & 87 & 6.57 \\
\hline Climatologia(47)+variabilidade pluviométrica(9)+enchentes $(8)$ & 64 & 4.83 \\
\hline $\begin{array}{l}\text { Meio Ambiente(21)+resíduos sólidos/reciclagem(24)+qualidade ambiental e de } \\
\text { vida(15) }\end{array}$ & 60 & 4.53 \\
\hline Metodologia, Ensino da Geografia e Práticas Pedagógicas(49) & 49 & 3.70 \\
\hline
\end{tabular}

Org. L. Poltroniéri e L. Machado

Tabela 6 - Agrupamento das palavras-chave das dissertações e teses no período 1992/2008 (n=370) - temas em nítido processo de consolidação.

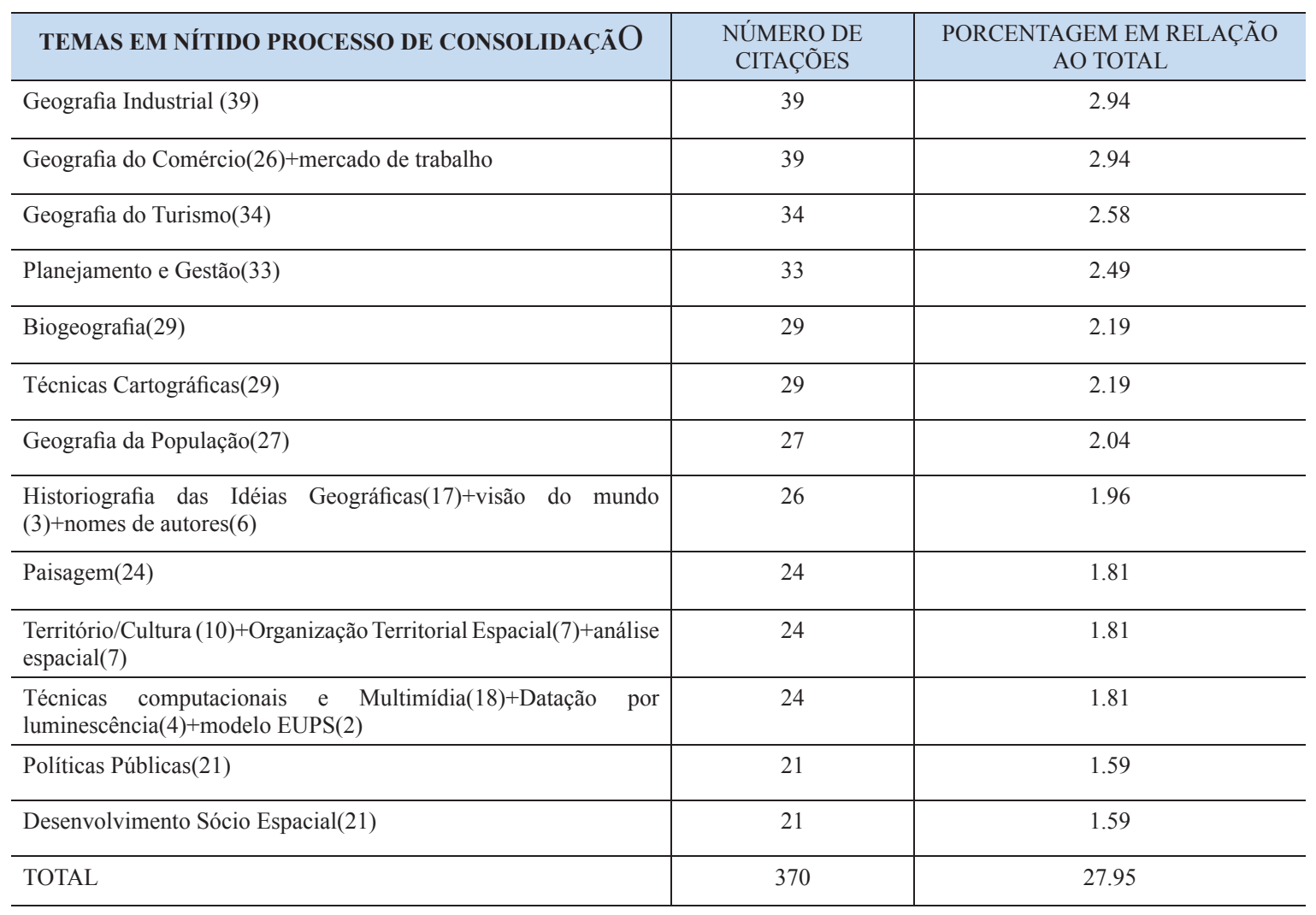

Org. L. Poltroniéri e L. Machado 
Tabela 7 - Agrupamento das palavras-chave das dissertações e teses no período 1992/2008 ( $\mathrm{n}=132)$ - questões centrais.

\begin{tabular}{l|c|c}
\hline \multicolumn{1}{c|}{ QUESTÕES CENTRAIS } & $\begin{array}{c}\text { NÚMERO DE } \\
\text { CITAÇÕES }\end{array}$ & $\begin{array}{c}\text { PORCENTAGEM EM } \\
\text { RELAÇÃO AO TOTAL }\end{array}$ \\
\hline Geografia(8)+Geografia Física(7)+Geografia Regional (3) & 18 & 1.37 \\
\hline SIG(16) & 16 & 1.21 \\
\hline Geografia Médica(13)+ Doenças(2) & 15 & 1.13 \\
\hline Pedologia(13) & 13 & 0.98 \\
\hline Sensoriamento Remoto(12) & 12 & 0.91 \\
\hline Unidades de Conservação(12) & 12 & 0.91 \\
\hline Geoprocessamento(12) & 12 & 0.91 \\
\hline Geografia dos Transportes(10) & 10 & 0.75 \\
\hline Educação Ambiental(10) & 10 & 0.75 \\
\hline Globalização(9) & 9 & 0.68 \\
\hline Brownfileds(5) & 5 & 0.38 \\
\hline TOTAL & $\mathbf{1 3 2}$ & $\mathbf{9 9 . 9 7}$ \\
\hline
\end{tabular}

Org. L. Poltroniéri e L. Machado

Como pode ser observado na tabelas 5,6 e 7, a aplicação desta metodologia revelou a existência de três grandes eixos temáticos de pesquisa no Programa de Pós-Graduação em Geografia da UNESP/Rio Claro, no período 1992/2008:

a) EIXOS TEMÁTICOS CONSOLIDADOS e que permanecem até os dias atuais, que incluem aquelas palavras-chave que foram citadas de $11 \%$ a $36 \%$ dos trabalhos produzidos;

b) TEMAS DE PESQUISA em nítido processo de consolidação que incluem aquelas palavras-chave que foram citadas de $5 \%$ a menos de $11 \%$ dos trabalhos produzidos ;

c) QUESTÕES CENTRAIS com considerável número de trabalhos já realizados e que se destacam na produção científica do Programa, que incluem palavras-chave que foram citadas de $1 \%$ a menos de $5 \%$ dos trabalhos produzidos.

Tais resultados fornecem, certamente, importante subsídio para o direcionamento das reflexões sobre a necessidade de reestruturar o número e a nomenclatura das linhas de pesquisa, de acordo com as tendências que os projetos dos Pós-Graduandos estão seguindo, sem esquecer, é claro, a Área de Concentração do Programa, que é a Organização do Espaço.

Nesta análise qualitativa categorial foram encontradas várias dificuldades, principalmente relacionadas, em alguns casos, à falta de objetividade na escolha das palavras-chave que melhor definem o trabalho e, em outros, ao não atendimento à Norma do Programa que exige a colocação de até seis palavras-chave.

No primeiro aspecto, notou-se, em vários casos, a indicação de palavras sem nenhuma representatividade perante o trabalho fazendo com que o leitor, apenas mediante as palavras-chave indicadas, não consiga inferir a que temática se refere a pesquisa. Citam-se, como exemplos: "contribuições e originalidades"; "transformações"; "padrões"; "sujeitos".

Quanto ao segundo aspecto, muitas vezes, foi colocada uma frase pertinente ao assunto, ao invés de citar até seis palavras-chave como determina a Norma do Conselho do Programa datada de novembro/1992, dificultando o trabalho de coleta.

De todo modo, a análise das palavras-chave revelou-se extremamente importante para determinar a relevância da produção científica do Programa. Da forma como foi realizado o agrupamento ficou claro que considerar apenas a repetição das palavras-chave idênticas empobreceria, 
sobremaneira, os resultados desta pesquisa. Consequentemente, não seria possível determinar os eixos temáticos historicamente presentes no Programa, perdendo-se muito em qualidade e nível de detalhamento.

A decisão de ampliar o agrupamento considerando a similaridade e/ou a sinonímia das palavras-chave foi fundamental para a eficácia da metodologia aplicada.

Deste modo, docentes e alunos têm extrema responsabilidade na definição e inclusão de palavras-chave nas pesquisas para evitar a perda de informações valiosas, as quais definem o perfil temático do Programa.

\section{CONSIDERAÇÕES FINAIS}

A freqüente reestruturação das linhas de pesquisa dos Programas de Pós-Graduação em Geografia é uma tendência geral no Brasil. Estudos detalhados sobre o tema reconhecem a importância da criação de novos Cursos e também da ampliação e da modernização das linhas de pesquisa.

O mundo, em suas relações sócio-espaciais, muda de maneira veloz e, nessa dinâmica, novos temas emergem e a Geografia também tem incessantemente procurado compreender as novas questões que vão sendo colocadas pelas diversas realidades.

A citação seguinte demonstra, dentro desse contexto, o importante papel da ANPEGE no acompanhamento das novas técnicas brasileiras da Pós-Graduação em Geografia.

Ao nosso ver, a ANPEGE alcança, hoje, sua maturidade num momento em que a Pós-Graduação em Geografia no Brasil se consolida, como área de produção científica e conhecimento em toda a sua diversidade. Nesse sentido, além da criação de novos cursos, cabe salientar a ampliação de linhas de pesquisas capazes de atrair o interesse de jovem pesquisadores, bem como o paulatino aperfeiçoamento de professores. ( SILVA e OLIVEIRA, p.119, 2009)

No que tange à auto-avaliação, a realização desta pesquisa baseada no agrupamento de palavras-chave por similaridade revelou-se um valioso instrumento para embasar, objetivamente, as discussões em torno da reestruturação de linhas de pesquisa. Observou-se que o Programa ora optou pela pulverização, com grande número de linhas de pesquisa, ora pela excessiva concentração quando, desde 2007, por exemplo, foram estabelecidas apenas 2 linhas de pesquisa.

No decorrer da história do Programa de Pós-Graduação em Geografia da UNESP/Rio Claro, a sistemática de auto-avaliação evidenciou, depois de várias experiências de reestruturação das linhas de pesquisa, a necessidade de estabelecer uma análise baseada, unicamente, em sua efetiva produção acadêmica. A referida análise realizada em um período de dezessete anos (1992/2008) retratou, fielmente, os grandes eixos temáticos que foram pesquisados ao longo desses anos, embora, muitos deles estivessem presentes desde o início do Programa:

. os consolidados, que correspondem a 600 citações e $45,32 \%$ do total de palavras-chave pesquisado;

. aqueles em nítido processo de consolidação, com 370 citações e 27,95\% do total pesquisado;

. questões centrais que estão despontando na produção científica do Programa, com 132 citações e $9,97 \%$ do total pesquisado.

Estes três eixos temáticos que aglutinaram 1102 palavras-chave correspondem a 83,44\% do total pesquisado (1324). Este percentual, somado àquele relativo aos estudos de caso $(7,70 \%)$ totaliza um aproveitamento de palavras-chave no agrupamento, da ordem de 90,94\%.

Este percentual extremamente alto, aliado ao longo período que foi considerado para a análise (1992/2008), conferem aos resultados desta pesquisa, alto grau de confiabilidade, o que permite que 
a metodologia proposta possa ser utilizada por qualquer Programa de Pós-Graduação, em qualquer período, com as devidas adaptações.

Cabe às próximas gestões do Programa o desafio de, com base nesse minucioso levantamento, iniciar um novo debate, análises e posicionamentos conclusivos sobre a relevância de, finalmente, reestruturar as linhas de pesquisa com base no que de fato vem sendo produzido neste Programa.

É chegada a hora de rever os objetivos e temas que estão sendo avaliados, atribuindo seus significados para a ciência geográfica. A reestruturação das linhas de pesquisa deve ser uma prática abrangente, que busque compreender e qualificar todas as ações e decisões, as quais vão desde o processo seletivo, passando pelas disciplinas oferecidas e resultando nas Teses e Dissertações produzidas.

Reestruturar as linhas de pesquisa significa aperfeiçoar o Programa, preservando e ampliando suas conquistas. Afinal, o Programa de Pós-Graduação em Geografia de Rio Claro sempre produziu uma Geografia de vanguarda, nunca de omitindo em atender ao compromisso de fazer com que os pesquisadores ali formados contribuíssem ativamente na escrita da história da Geografia brasileira, construindo propostas e embasando decisões na busca do conhecimento

Os levantamentos, as dificuldades, as críticas e as proposições apresentadas neste artigo, indicam novas perspectivas e ações necessárias para que o Programa continue, por meio de uma transformação coletiva, rumo à manutenção e aperfeiçoamento da qualidade da formação acadêmico-científica, tanto para seus alunos como para seus docentes pesquisadores.

\section{REFERÊNCIAS BIBLIOGRÁFICAS}

FREIRE, Paulo. A importância do ato de ler em três artigos que se completam. 31. Ed. São Paulo: Cortez, 1990. 80p.

SAUL, A. M. A sistemática de auto-avaliação do Programa de Pós-Graduação em Educação (Currículo) da PUC-SP. Estudos em Avaliação Educacional, n.26, jul-dez, p.97-109, 2002.

GALVÃO, M do C. C. Reflexões sobre as atividades de orientação em pós-graduação. Revista da ANPEGE. V.3, p.3 - 16, 2007.

CARLOS, A. F. A. Questões para a construção de uma política de pós-graduação em geografia. Revista da ANPEGE ano 1, $\mathrm{n}^{\circ} 1$ Curitiba, PR 2003.

DUARTE, G. M. A pesquisa e a Pós-Graduação em Geografia no Brasil - Os dez anos da ANPEGE. Revista da ANPEGE ano 1, n 1 Curitiba, PR 2003.

GERARDI, L. H de O. ANPEGE: O resgate de uma história. Revista da ANPEGE, ano $1, \mathrm{n}^{\circ} 1$ Curitiba, PR 2003.

MENDONÇA, F. Temas, Tendências e Desafios da Geografia na Pós-Graduação Brasileira. Revista da ANPEGE ano 2, n 2 Fortaleza, CE 2005.

SILVA, J. B. e DANTAS, E. W. C. A pós-graduação em Geografia no Brasil:uma contribuição à política de avaliação. Revista ANPEGE, São Paulo, 2005.

SUERTEGARAY, D. M. A. A expansão da pós-graduação em Geografia no Brasil e a ANPEGE. Revista da ANPEGE, ano 1, n¹, Curitiba,Paraná, 2003.

SUERTEGARAY, D. M. A. O atual e as tendências do ensino e da pesquisa em Geografia no Brasil. Revista do Departamento de Geografia (USP), São Paulo, v.16, p.38-45, 2005.

SUERTEGARAY, D. M. A. Rumos e Rumores da Pós- Graduação e da Pesquisa em Geografia no Brasil. Revista da ANPEGE. V.3, p.17-31, 2007.

SILVA, J.B e OLIVEIRA, M.P. A trajetória da pós-graduação no Brasil e a ANPEGE: Algumas questões sociais. Revista da ANPEGE, v.5, p.106-122, 2009. 